\title{
Expression of extracellular matrix components and their receptors in the central nervous system during experimental Toxoplasma gondii and Trypanosoma cruzi infection
}

\author{
A.A. Silva ${ }^{1,2}$, \\ E. Roffê ${ }^{1}$ and \\ J. Lannes-Vieira ${ }^{1}$
}

\author{
Correspondence \\ J. Lannes-Vieira \\ Departamento de Imunologia \\ Instituto O swaldo Cruz, FIOCRUZ \\ Av. Brasil, 4365 \\ 21045-900 Rio de Janeiro, RJ \\ Brasil \\ Fax: + 55-21-280-1589 \\ E-mail: lannes@ gene.dbbm.fiocruz.br \\ Presented at the 5th Brazilian \\ Symposium on Extracellular \\ Matrix - SIMEC, Angra dos Reis, \\ RJ, Brasil, September 7-10, 1998. \\ Research supported by CNPq, CAPES, \\ IOC, and PAPES-Fiocruz.
}

Received January 22, 1999 Accepted February 2, 1999

\author{
${ }^{1}$ Departamento de Imunologia, Instituto O swaldo Cruz, FIOCRUZ, \\ Rio de Janeiro, RJ, Brasil \\ 2Departamento de Patologia, U niversidade Federal Fluminense, \\ Niterói, RJ, Brasil
}

\section{Abstract}

Alterations in extracellular matrix (ECM) expression in the central nervous system (CNS) usually associated with inflammatory lesions have been described in several pathological situations including neuroblastoma and demyelinating diseases. The participation of fibronectin (FN) and its receptor, the VLA-4 molecule, in the migration of inflammatory cells into the CNS has been proposed. In Trypanosoma cruzi infection encephalitis occurs during the acute phase, whereas in Toxoplasma infection encephalitis is a chronic persisting process. In immunocompromised individuals such as AIDS patients, T. cruzi or $T$. gondii infection can lead to severe CNS damage. At the moment, there are no data available regarding the molecules involved in the entrance of inflammatory cells into the CNS during parasitic encephalitis. Herein, we characterized the expression of the ECM components FN and laminin (LN) and their receptors in the CNS of T. gondii- and $T$. cruzi-infected mice. An increased expression of FN and LN was detected in the meninges, leptomeninges, choroid plexus and basal lamina of blood vessels. A fine FN network was observed involving $T$. gondii-free and $T$. gondii-containing inflammatory infiltrates. Moreover, perivascular spaces presenting a FN-containing filamentous network filled with $\alpha 4^{+}$and $\alpha 5^{+}$cells were observed. Although an increased expression of LN was detected in the basal lamina of blood vessels, the CNS inflammatory cells were $\alpha 6$-negative. Taken together, our results suggest that FN and its receptors VLA-4 and VLA5 might be involved in the entrance, migration and retention of inflammatory cells into the CNS during parasitic infections.

\section{Key words}

- Toxoplasma gondii

- Trypanosoma cruzi

- Central nervous system

- Extracellular matrix 


\section{Introduction}

The central nervous system (CNS) is considered to be an immunoprivileged site able to restrict the entry of inflammatory cells. In Chagas' disease, a parasitic infection caused by Trypanosoma cruzi, meningoencephalitis rarely occurs (1). It is more frequently found during the acute stage of infection in children under 2 years of age and in immunosuppressed transplanted or AIDS patients, the latter usually presenting symptoms compatible with reactivation of the disease (1-4). The neuropathologic picture produced by experimental infection with $T$. cruzi in immunocompetent animals showed amastigote forms and parasite antigens in neurons, glial and microglial cells. The presence of encephalitis in multiple foci of variable intensity and random distribution, with nodular arrangement of the inflammatory mononuclear cells, has been reported (5-7). Toxoplasma gondii infection is another parasitic disease with involvement of the CNS. This infection is usually controlled by the host immune system, resulting in an asymptomatic chronic infection maintained by dormant parasitic cysts, mainly in nervous tissue (8). In immunocompromised individuals the infection with $T$. gondii can lead to severe CNS damage (9). Also, intense inflammatory infiltrates with irregular distribution composed mainly of macrophage, $\mathrm{CD} 8^{+}$and $\mathrm{CD} 4^{+}$ $T$ cells $(10,11)$ have been observed in the CNS during experimental toxoplasmic infection.

In the nervous system, extracellular matrix (ECM) components participate in various physiological processes regulating cell migration, proliferation and axonal pathfinding $(12,13)$. Alterations in ECM expression in the CNS have been observed in several pathological situations including demyelinating diseases and neuroblastoma $(12,14-$ 16). In demyelinating diseases such as experimental allergic encephalomyelitis (EAE), a fibronectin (FN)-containing network is observed in the perivascular cuffs (16). In addition, recent studies have shown that in EAE the VLA-4 integrin, a ligand for FN and the adhesion molecule VCAM-1, is involved in the entrance of antigen-specific activated $\mathrm{CD}^{+} \mathrm{T}$ cells into the CNS leading to demyelination $(17,18)$. Increased expression of soluble fibronectin in serum (19) and alterations of ECM expression in cardiac tissue have been reported to occur during experimental T. cruzi infection (20; Santos PVA and Lannes-Vieira $J$, unpublished data). Moreover, a recent study showed that antibodies recognizing laminin (LN) and its receptor the VLA-6 molecule are able to block the migration of splenic $\mathrm{CD}^{+} \mathrm{T}$ cells obtained from chronically $T$. cruzi-infected mice to cardiac tissue, suggesting the participation of these molecules in the migration of $\mathrm{T}$ cells into the inflamed myocardium during experimental chagasic infection (21). However, there are no available data concerning the molecules involved in the entrance of inflammatory cells into the CNS during parasitic infections. To address this question, we studied the expression of the ECM components and their receptors in the CNS of $T$. gondii- and T. cruzi-infected mice.

\section{Material and Methods}

\section{Animals}

Female $\mathrm{C} 3 \mathrm{H} / \mathrm{He}$ and $\mathrm{C} 57 \mathrm{BL} / 6$ mice (5-7 weeks old) were obtained from the Animal Facilities, Bio-Manguinhos, Fundação Oswaldo Cruz. Groups of 10 animals were kept in polypropylene cages with food and water ad libitum throughout the experiments.

\section{T. cruzi infection}

Female $\mathrm{C} 3 \mathrm{H} / \mathrm{He}$ mice were infected intraperitoneally with 100 blood trypomastigote forms of the Colombian type III strain of T. cruzi (22), maintained by serial passages in $\mathrm{C} 3 \mathrm{H} / \mathrm{He}$ mice. Parasitemia was esti- 
mated according to Brener's method (23), and employed as a parameter to establish the acute (42 days post-infection) and chronic (90 days post-infection) phases.

\section{T. gondii infection}

Experimental toxoplasmosis was induced in female C57BL/6 mice by injecting intraperitoneally 15 cysts of the ME-49 strain of T. gondii. As previously determined (8), the animals were sacrificed during the acute (20 days post-infection) and chronic phases (46 days post-infection).

\section{Antibodies}

Polyclonal antibodies specific for the ECM proteins FN and $\mathrm{LN}$ and monoclonal antibodies recognizing the $\alpha 4, \alpha 5$ and $\alpha 6$ chains of the VLA molecules were purchased from PharMingen (San Diego, CA, USA). The specific antibody recognizing $T$. cruzi antigens was a gift from Dr. Rosa Teixeira de Pinho (Department of Immunology, Oswaldo Cruz Institute, Brazil). Biotinylated antibodies recognizing rat or rabbit immunoglobulin and the peroxidase-streptavidin complex were purchased from Amersham International (Buckinghamshire, England). Appropriate controls were prepared by replacing primary antibodies with purified rat immunoglobulin or normal rabbit serum.

\section{Histopathological studies}

Groups of 5 mice were submitted to cardiac perfusion with saline $(200 \mathrm{ml}$ per animal) under anesthesia and sacrificed at various times post-infection. Groups of 3 agematched control mice were sacrificed at the same times. The encephalon was removed, embedded in tissue-freezing medium (Tissue Tek, Miles Laboratories, Clifton, NJ, USA) and stored in liquid nitrogen. Serial sections 5-7 $\mu \mathrm{m}$ thick were prepared by sagittal cuts and fixed in cold acetone. These sections were stained with hematoxylin and eosin or submitted to indirect immunoperoxidase.

\section{Immunohistochemistry}

The indirect immunoperoxidase technique was used as previously described (24). Briefly, serial cryostat sections were mounted on poly-L-lysine-covered glass slides and fixed for $10 \mathrm{~min}$ in cold acetone. Endogenous peroxidase and nonspecific antibody binding were blocked by incubating the specimens with PBS containing $0.1 \%$ sodium azide and normal goat serum (diluted 1/50). Next, we performed sequential incubations with primary unlabeled antibodies or speciesmatched control Igs, secondary biotinylated antibodies (goat anti-rabbit Ig or goat antirat Ig) and the streptavidin-peroxidase complex. All incubations were performed for $1 \mathrm{~h}$ with antibodies diluted in 1\% PBS-BSA and were followed by washes in PBS. The peroxidase reaction was developed with aminoethylcarbazole in the presence of hydrogen peroxide. The material was counterstained with Mayer's hematoxylin and analyzed under the light microscope.

\section{Results}

$\mathrm{C} 57 \mathrm{BL} / 6$ and $\mathrm{C} 3 \mathrm{H} / \mathrm{He}$ mice were infected with the ME-49 strain of $T$. gondii and the Colombian strain of T. cruzi, respectively, to analyze the expression of ECM components and their receptors in the CNS during parasitic infections. Initially, the pathological alterations present in the CNS during these infections were characterized. Intense inflammatory infiltrates localized mainly in areas of incomplete blood-brain barrier, meninges, leptomeninges, choroid plexus and basal lamina of blood vessels were observed during the acute phase of experimental $T$. gondii and T. cruzi infection (data not shown). During chronic infection, isolated $T$. gondii cysts without surrounding inflammatory in- 
filtrates (Figure 1a) were frequently observed, although inflammatory infiltrates associated with cysts and $T$. gondii-free inflammatory infiltrates were also detected (Figure 1b). As previously reported, also in experimental chagasic infection the inflammatory infiltrates were frequently not related to the presence of T. cruzi-antigen (Silva AA, Marino APM, Santos PVA, Roffê E, Quirico-Santos T, Paiva $\mathrm{CN}$ and Lannes-Vieira J, unpublished data). In contrast to T. cruzi infection which presents a self-resolving acute encephalitis, the inflammatory infiltrates were more intense during the chronic phase of $T$. gondii infection (Table 1).

As a first attempt to determine which molecules are involved in the migration of inflammatory cells into the CNS during parasitic infections, we performed immunohistochemical assays for the detection of ECM components, namely FN and LN. There was an increased expression of FN and LN in the CNS of both acute and chronically $T$. gondiiand $T$. cruzi-infected mice when compared to the pattern found in uninfected controls (Table 1). The increased FN expression was detected mainly in the meninges, leptomeninges, cerebellum and basal lamina of blood

Table 1 - The presence of parasite antigens and inflammatory infiltrates, and the expression of ECM components and their receptors in the CNS of T. gondii- and T. cruzi-infected mice.

The occurrence/intensity of the analyzed parameters was scored as follows: +++, many; ++, moderate amounts; +, few; \pm , very few; -, negative staining. NT, Not tested; FN, fibronectin; LN, laminin.

\begin{tabular}{|c|c|c|c|c|c|c|}
\hline \multirow[t]{3}{*}{ Analyzed parameter } & \multicolumn{6}{|c|}{ Experimental groups } \\
\hline & \multicolumn{3}{|c|}{ T. gondii } & \multicolumn{3}{|c|}{ T. cruzi } \\
\hline & Uninfected & Acute & Chronic & Uninfected & Acute & Chronic \\
\hline T. gondii cysts & - & - & ++ & NT & NT & NT \\
\hline T. cruzi antigen & NT & NT & NT & - & + & - \\
\hline Inflammatory infiltrates & - & ++ & +++ & - & +++ & \pm \\
\hline FN & + & ++ & ++ & + & ++ & ++ \\
\hline$\alpha 4$ & - & ++ & + & \pm & + & \pm \\
\hline$\alpha 5$ & - & ++ & + & \pm & + & \pm \\
\hline LN & ++ & +++ & +++ & ++ & +++ & +++ \\
\hline$\alpha 6$ & \pm & + & + & \pm & + & + \\
\hline
\end{tabular}

vessels in both infections (data not shown). Also, a fine FN filamentous network involving $T$. gondii-free and $T$. gondii-containing inflammatory infiltrates was frequently observed in the CNS parenchyma (Figure 1c). Although an increased expression of LN was found in the basal lamina of blood vessels, choroid plexus, meninges and leptomeninges of acute and chronically $T$. gondii- and $T$. cruzi-infected mice, the expression of this molecule was not associated with the presence of inflammatory infiltrates (Figure 1d).

Immunohistochemical assays were also applied to investigate the expression of ECM receptors in the CNS. The blood vessels present in the brain tissue of acutely $T$. gondiiand $T$. cruzi-infected mice showed intense expression of $\alpha 4$ and $\alpha 5$ molecules. Also, perivascular spaces presenting a FN-containing filamentous network filled with $\alpha 4$ (Figure 2a,b) and $\alpha 5$-bearing cells were detected during acute infection. Although the expression of the $\mathrm{LN}$ and $\alpha 6$ molecules was detected in the endothelial layer of blood vessels, the CNS infiltrating mononuclear cells were $\alpha 6$-negative (Figure $2 \mathrm{c}, \mathrm{d}$ ). In $T$. gondii-infected mice the intense alterations in expression of $\alpha 4$ and $\alpha 5$ molecules observed during acute infection persisted during the chronic phase. In contrast, during chronic $T$. cruzi infection a slightly increased expression of $\alpha 4$ and $\alpha 5$ molecules restricted to the endothelial layer of blood vessels was detected. These data are summarized in Table 1.

\section{Discussion}

In the present study we investigated the pattern of ECM components and their receptors in the central nervous system during parasitic infections. We observed an increased expression of $\mathrm{FN}$ and $\mathrm{LN}$ during the acute and chronic stages of experimental $T$. gondii and T. cruzi infection similar to that observed in the CNS in other inflammatory processes, such as tumors and autoimmune 
diseases (14-16). During the acute phase of both $T$. gondii and $T$. cruzi infection, the appearance of a fine FN-containing network in the enlarged perivascular spaces coincided with the formation of mononuclear inflammatory infiltrates, suggesting the par-
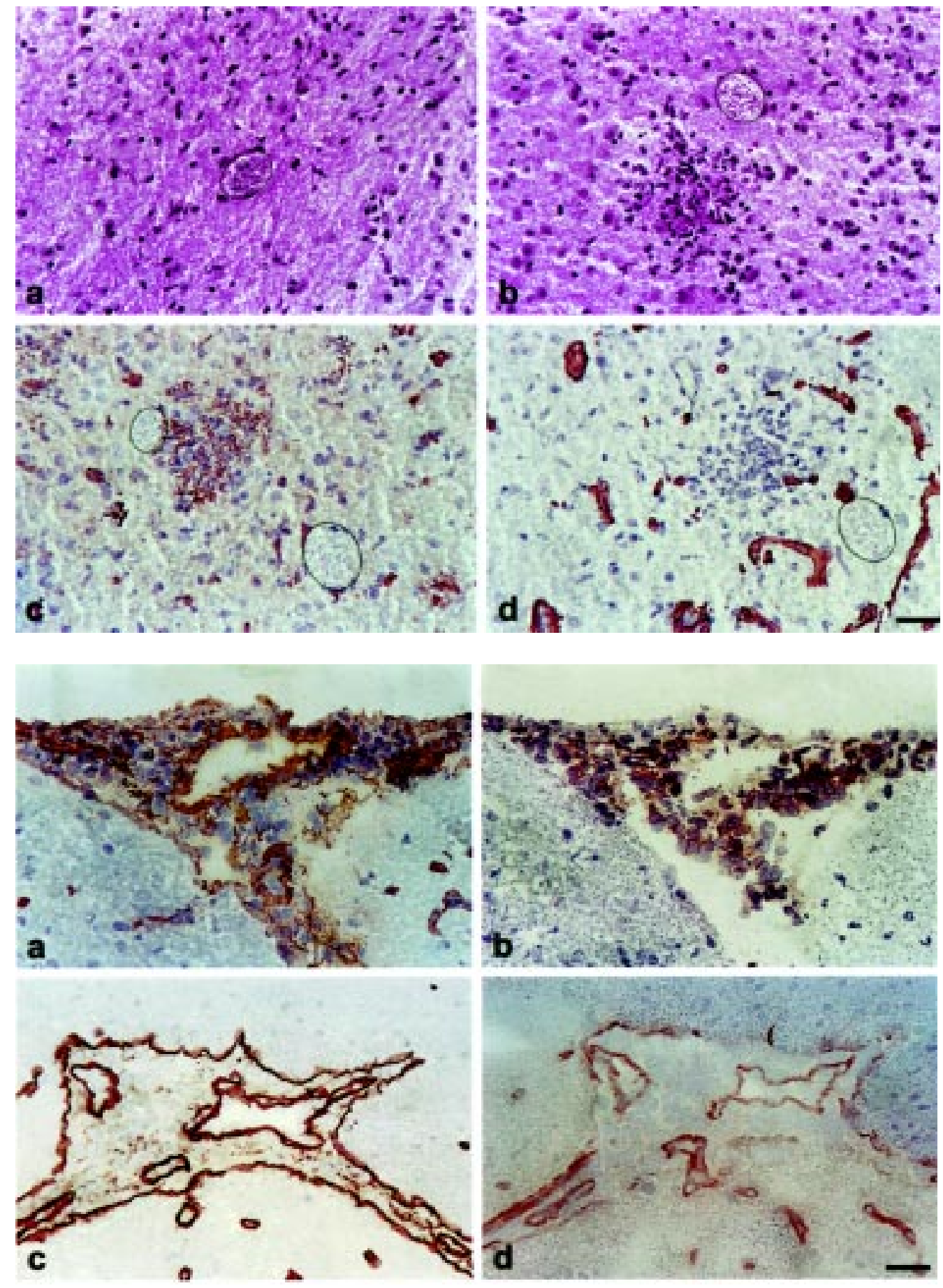

ticipation of this ECM glycoprotein in the migration of inflammatory cells into the CNS during these infections. In multiple sclerosis and experimental allergic encephalomyelitis the altered expression of FN in the CNS was paralleled by the formation of inflammatory
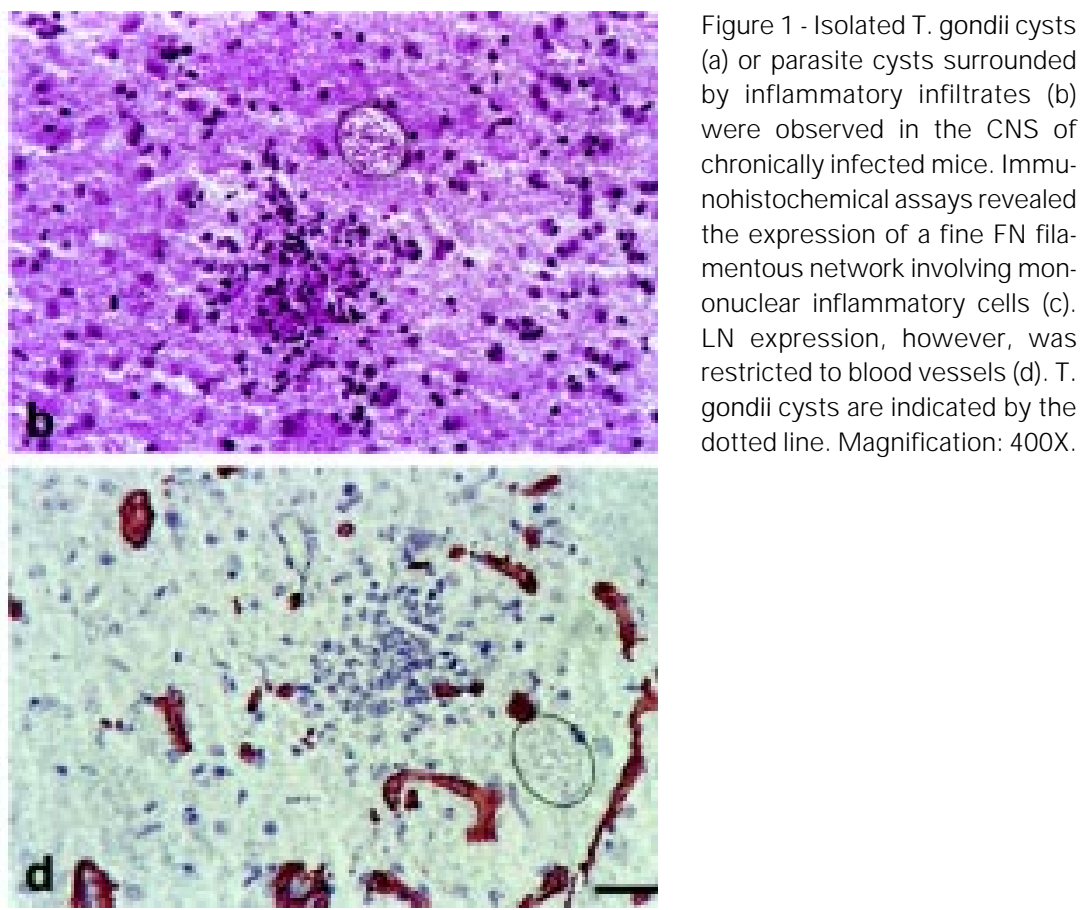

Figure 2 - A FN-containing network (a) was observed involving $\alpha 4^{+}$inflammatory cells (b) present in the meninges of chronically $\mathrm{T}$. gondii-infected mice. $\mathrm{LN}$ (c) and $\alpha 6$ (d) were detected in the endothelial cells of blood vessels whereas the mononuclear cells were $\alpha 6$-negative. Magnification: 400X. 
perivascular cuffs $(15,16)$. These findings led to the proposal that ECM components participate in the establishment of chronic inflammation during autoimmune processes.

Interestingly, the presence of a fine FN filamentous network was observed involving $T$. gondii-free and $T$. gondii-containing inflammatory infiltrates. On the other hand, LN was not detected by our immunohistochemical assays in these inflammatory infiltrates, suggesting a more effective involvement of FN in the genesis of CNS inflammatory lesions during $T$. gondii infection. Concerning the origin of this $\mathrm{FN}$, it is possible that nervous or mononuclear cells present in the inflammatory infiltrates could release ECM molecules in nervous tissue (25-27). Indeed, some studies have demonstrated that motor neurons, glial cells and astrocytes are able to secrete ECM molecules such as FN and LN when neuronal-glial interaction occurs and during the astrocyte proliferative response following injury $(25,26)$.

The modulators and the mechanisms leading to the alterations in ECM expression in the CNS during parasitic infections are unknown. We may speculate that corticoids or cytokines such as IFN- $\gamma$ and TNF- $\alpha$, which have been shown to modulate ECM expression $(24,28,29)$ and to be systemically enhanced during Chagas' infection (30-32) and toxoplasmosis $(11,33,34)$, could modulate ECM expression in the CNS during parasitic diseases besides contributing to damage to the blood-brain barrier. During the chronic stage of $T$. cruzi infection the CNS inflammation does not persist, although an increased expression of ECM was still observed in the basal lamina of blood vessels. It is possible that the soluble molecules such as cytokines produced systemically or locally by the few inflammatory cells restricted to areas of incomplete blood-brain barrier could account for the alterations in ECM expression. Also, the altered ECM expressed in the CNS may contribute to the generation/perpetuation of the observed encephalitis, stabilizing and presenting cytokines to inflammatory cells $(35,36)$.

ECM molecules play an important role in the host cell-parasite interaction (37,38). In this study we did not observe an association between the presence of parasite cysts or antigens and $\mathrm{FN}$ or $\mathrm{LN}$ expression in the infected tissues. However, in vitro studies showed that L929 fibroblasts and $\mathrm{C} 2 \mathrm{C} 12$ muscle cells infected with $T$. cruzi or treated with shed parasite antigens present an increased expression of ECM proteins (Pinho RT and Lannes-Vieira J, unpublished results). Thus, parasite antigens present in CNS lesions as a result of antigen shedding or parasite clearance by immune cells could induce inflammatory and/or nervous cells to produce ECM molecules. Further studies are required to examine this possibility.

Regarding the expression of ECM receptors, we showed that the enhancement of FN expression is accompanied by an increased expression of $\alpha 4$ and $\alpha 5$ and by the appearance of $\alpha 4$ - and $\alpha 5$-bearing inflammatory cells during the acute phase of $T$. cruzi infection and during acute and chronic Toxoplasma encephalitis. Conversely, the increased expression of $\mathrm{LN}$ detected in the basal lamina of blood vessels was not paralleled by the presence of $\alpha 6$ on the surface of infiltrating mononuclear cells. The presence of $\alpha 4^{+}$and $\alpha 5^{+}$mononuclear cells inside a FN-containing network suggests the participation of these molecules in the migration of immune cells into the CNS leading to the development of inflammatory processes during parasitic diseases. In fact, this possibility is supported by the findings that antibodies recognizing the VLA-4 molecule, but not antibodies against other adhesion molecules, effectively prevented the accumulation of leukocytes in the CNS and the development of encephalomyelitis in Lewis rats. Also, in in vitro experiments, anti- $\alpha 4$ antibody selectively blocked the binding of lymphocytes to inflamed endothelial cells $(17,18)$. Recently, it was demonstrated in a murine model of 
encephalomyelitis that after transmigration throughout endothelial layer and migration into the brain parenchyma $T$ cells lose or down-regulate the expression of VLA-4 (39). On this basis, we cannot exclude the possibility that the $\alpha 6$ molecule could play a role in the migration of inflammatory cells into the CNS, being lost or down-regulated after transmigration. This possibility is supported by the demonstration that LN and VLA-6 play an important role in the entrance of $\mathrm{CD}^{+}$cells obtained from chronically $T$. cruzi-infected mice into cardiac tissue (21). However, we should also consider the possibility that the inflammatory processes present in the CNS and myocardium of T. cruziinfected mice have different origins, with different specificity and functional activity of the cell populations involved. Since the encephalitis is a self-resolving process and the myocarditis is a chronic persisting inflammation, then differences in the ECM receptor status of these cell populations are expected.

Taken together, our results suggest that ECM components and their receptors play a role in the extravasation and migration of inflammatory cells into the CNS during experimental parasitic infections. The factors responsible for the entry and retention of lymphocytes within the CNS during parasitic infections including cytokines and chemokines are currently under investigation in our laboratory.

\section{Acknowledgments}

The authors are grateful to Marcos Gustavo Silva Ribeiro and Genilton Vieira for preparing the figures.

\section{References}

1. Pittella J EH (1993). Central nervous system in Chagas' disease. An updating. Revista do Instituto de Medicina Tropical, 35: 111-116.

2. Rocha $A$, Meneses $A C O$, Silva AM, Ferreira MS, Nishioca SA, Burgarelli MKN, Almeida E, Turcato-J r G, Metze K \& Lopes ER (1994). Pathology of patients with Chagas' disease and acquired immunodeficiency syndrome. American J ournal of Tropical Medicine and Hygiene, 50: 261268.

3. Prata A (1994). Chagas' disease. Infectious Disease Clinics of North America, 8: 61-76.

4. Pentreath VW (1995). Trypanosomiasis and the nervous system. Pathology and immunology. Transactions of the Royal Society of Tropical Medicine and Hygiene, 89: 9-15.

5. Torres M \& Villaça J (1919). Encefalite e mielite cauzadas por um Tripanozoma (T. cruzi). Memórias do Instituto Oswaldo Cruz, 11: 80-89.

6. Pittella J EH, Meneguette C, Barbosa AJ A \& Bambirra EA (1990). Histopathological and immunohistochemical study of the brain in the acute and chronic phases of experimental trypanosomiasis cruzi in dogs. Annals of Tropical Medicine and
Parasitology, 84: 615-621.

7. Pittella J EH (1991). Central nervous system involvement in experimental trypanosomiasis cruzi. Memórias do Instituto Oswaldo Cruz, 86: 141-145.

8. Gazzinelli RT, Denkers EY \& Sher A (1993). Host resistance to Toxoplasma gondii: model for studying the selective induction of cell-mediated immunity by intracellular parasites. Infectious Agents and Disease, 2: 139-149.

9. Hunter CA \& Remington JS (1994). Immunopathogenesis of toxoplasmic encephalitis. J ournal of Infectious Diseases, 170: 1057-1067.

10. Schlüter $D$, Deckert-Schlüter $M$, Schwendemann $\mathrm{G}$, Brunner $\mathrm{H} \&$ Hof $\mathrm{H}$ (1993). Expression of major histocompatibility complex class II antigens and levels of interferon- $\gamma$, tumour necrosis factor, and interleukin-6 in cerebrospinal fluid and serum in Toxoplasma gondii-infected SCID and immunocompetent C.B-17 mice. Immunology, 78: 430-435.

11. Gazzinelli RT, Brézin A, Li Q, Nussenblatt RB \& Chan CC (1994). Toxoplasma gondii: Acquired ocular toxoplasmosis in the murine model, protective role of TNF- $\alpha$ and IFN- $\gamma$. Experimental Parasitology, 78: 217229.
12. Venstrom KA \& Reichardt LF (1993). Extracellular matrix II: Role of extracellular matrix molecules and their receptors in the nervous system. FASEB J ournal, 7: 996-1003.

13. Gilat $D$, Cahalon L, Hershkoviz R \& Lider O (1996). Interplay of T cells and cytokines in the context of enzymatically modified extracellular matrix. Immunology Today, 17: 16-20.

14. Pilkington GJ (1996). The role of the extracellular matrix in neoplastic glial invasion of the nervous system. Brazilian J ournal of Medical and Biological Research, 29: 1159-1172.

15. Sobel RA \& Mitchell ME (1989). Fibronectin in multiple sclerosis lesions. American J ournal of Pathology, 135: 161-169.

16. Shin T, Kojima T, Tanuma N, Ishihara $Y \&$ Matsumoto $Y$ (1995). The subarachnoid space as a site for precursor $T$ cell proliferation and effector cell selection in experimental autoimmune encephalomyelitis. J ournal of Neuroimmunology, 56: 171177.

17. Yednock TA, Cannon C, Fritz LC, SanchezMadrid F, Steinman L \& Karin N (1992). Prevention of experimental autoimmune encephalomyelitis by antibodies against $\alpha 4 ß 1$ integrin. Nature, 356: 63-66. 
18. Baron J L, Madri J A, Ruddle NH, Hashim $G \& J$ aneway J r CA (1993). Surface expression of $\alpha 4$ integrin by CD4 T cells is required for their entry into brain parenchyma. J ournal of Experimental Medicine, 177: 57-68.

19. Truyens $C$, Rivera MT, Ouaissi A \& Carlier $Y$ (1995). High circulating levels of fibronectin and antibodies against its RGD adhesion site during mouse Trypanosoma cruzi infection: relation to survival. Experimental Parasitology, 80: 499-506.

20. Andrade SG, Grimaud JA \& StockerGuerret S (1989). Sequential changes of the connective matrix components of the myocardium (fibronectin and laminin) and evolution of cardiac fibrosis in mice infected with Trypanosoma cruzi. American J ournal of Tropical Medicine and Hygiene, 40: $252-260$

21. Silva-Barbosa SD, Cotta-de-Almeida V, Riederer I, De Meis J, Dardenne M, Bonomo A \& Savino W (1997). Involvement of laminin and its receptor in abrogation of heart graft rejection by autoreactive $T$ cells from Trypanosoma cruzi-infected mice. J ournal of Immunology, 159: 997-1003.

22. Andrade SG (1974). Caracterização de cepas do Trypanosoma cruzi isoladas no recôncavo baiano. Revista de Patologia Tropical, 3: 65-121.

23. Brener $Z$ (1962). Therapeutic activity and criterion of cure on mice experimentally infected with Trypanosoma cruzi. Revista do Instituto de Medicina Tropical, 4: 389394.

24. Lannes-Vieira J, Van Der Meide $\mathrm{PH} \&$ Savino W (1991). Extracellular matrix components of the mouse thymic microenvironment. II. In vitro modulation of basement membrane proteins by interferon- $\gamma$ : relationship with thymic epithelial cell pro- liferation. Cellular Immunology, 137: 329340.

25. Masuda-Nakagawa LM, Muller KJ \& Nicholls J G (1993). Axonal sprouting and laminin appearance after destruction of glial sheaths. Proceedings of the National Academy of Sciences, USA, 90: 49664970.

26. Niquet J (1994). Proliferative astrocytes may express fibronectin-like protein in the hippocampus of epileptic rats. Neuroscience Letters, 180: 13-16.

27. Alito K, Hovi T \& Vaheri A (1980). Fibronectin is produced by human macrophages. J ournal of Experimental Medicine, 151: 602-613.

28. Lannes-Vieira J , Dardenne M \& Savino W (1991). Extracellular matrix components of the mouse thymic microenvironment ontogenic studies and modulation by glucocorticoid hormones. J ournal of Histochemistry and Cytochemistry, 39: 15391546.

29. Fabry Z, Raine CS \& Hart MN (1994). Nervous tissue as an immune compartment: the dialect of the immune response in the CNS. Immunology Today, 15: 218-223.

30. Leite-de-Moraes MC, HontebeyrieJ oskowicz M, Leboulenger F, Savino W, Dardenne M \& Lepault F (1991). Studies on the thymus in Chagas' disease II. Thymocyte subset fluctuations in Trypanosoma cruzi-infected mice: Relationship to stress. Scandinavian J ournal of Immunology, 33: 267-275.

31. Silva J S, Morrissey PJ, Grabstein KH, Mohler KM, Anderson D \& Reed SG (1992). Interleukin 10 and interferon $\gamma$ regulation of experimental Trypanosoma cruzi infection. Journal of Experimental Medicine, 175: 169-174.

32. Starobinas $N$, Russo $M$, Minoprio $P \&$ Hontebeyrie-J oskowicz M (1991). Is TNF $\alpha$ involved in early susceptibility of Trypanosoma cruzi $\mathrm{C} 3 \mathrm{H} / \mathrm{He}$ mice? Research in Immunology, 142: 117-122.

33. Chang HR, Grau GE \& Pechere J C (1990). Role of TNF and IL-1 in infection with Toxoplasma gondii. Immunology, 69: 3337.

34. Langermanns J AM, van der Hust MEB Nibbering PH, Hiemstra PS, Transen L \& van Furth $\mathrm{R}$ (1992). IFN- $\gamma$ induced L-arginine dependent toxoplasmastatic activity in murine peritoneal macrophages is mediated by endogenous tumour necrosis factor- $\alpha$. J ournal of Immunology, 148: 568-574.

35. Alon A, Cahalon L, Hershkoviz R, Elboz D, Reizis B, Wallach D, Akiyama SK, Yamada KM \& Lider O (1994). TNF- $\alpha$ binds to the $\mathrm{N}$-terminal domain of fibronectin and augments the ß1-integrin-mediated adhesion of $\mathrm{CD}^{+} \mathrm{T}$ lymphocytes to the glycoprotein. J ournal of Immunology, 152: 13041322.

36. Hershkoviz R, Goldkom I \& Lider O (1995). Tumour necrosis factor- $\alpha$ interacts with laminin and functions as a pro-adhesive cytokine. Immunology, 85: 125-130.

37. Ouaissi MA (1988). Role of the RGD sequence in parasite adhesion to host cells. Parasitology Today, 4: 169-173.

38. Vannier-Santos MA, Saraiva EMB, Martiny A, Neves A \& De Souza W (1992). Fibronectin shedding by Leishmania may influence the parasite-macrophage interaction. European J ournal of Cell Biology, 59: 389397.

39. Romanic AM, Graesser D, Baron J L, Visintin I, J aneway CA \& Madri J A (1997). $T$ cell adhesion to endothelial cells and extracellular matrix is modulated upon transendothelial cell migration. Laboratory Investigation, 76: 11-23. 